\title{
Are community service doctors equipped to address priority health needs in South Africa?
}

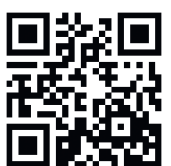

The social accountability of institutions which train doctors has attracted increasing attention in recent years. ${ }^{[1-3]}$ In this context, the World Health Organization (WHO) defines social accountability as 'an obligation to direct education, research and service activities towards addressing the priority health concerns of the community, region and/or nation they have a mandate to serve. ${ }^{\text {[4] }}$ While the 'social accountability debate' has gained considerable momentum, the essential healthcare needs of rural and/or underserved communities continue to be inadequately addressed globally. Unfortunately, the situation in South Africa (SA) is no different.

In an attempt to improve healthcare in rural and underserved areas, the Department of Health introduced 1 year of obligatory community service for all medical graduates in $1998 .{ }^{[5]}$ When it was decided that the 1-year programme didn't adequately prepare graduates for clinical practice, the Health Professions Council of South Africa (HPCSA) extended it to to 2 years in $2005{ }^{[6]}$ Since then, however, institutions training medical students and supervising interns have had no feedback about the alignment of clinical training with SA's priority health needs, particularly in vulnerable areas. Essentially the question is, are we training socially accountable doctors?

In this edition of the $S A M J$, Nkabinde et al. ${ }^{[7]}$ provide key information about the priority health needs of communities served by SA's district hospitals. While the study is restricted to community service doctors working in district facilities in KwaZulu-Natal, it is highly unlikely that the priority health needs it identifies are not representative of basic community needs across the country.

In this study, $78 \%$ of community service medical officers (COSMOs) perceived their internship training as 'good to excellent' in preparing them for community service, while also identifying essential healthcare needs they felt inadequately prepared to address. Of particular concern is the lack of knowledge and skills in the management of obstetric and medical emergencies, as well as basic anaesthetic skills. COSMOs did not feel confident to manage acute coronary syndromes, cardiac arrhythmias, paediatric resuscitation and intubation, antepartum haemorrhage, cord prolapse, breech delivery and eclampsia. They were also not confident in administering regional, spinal or general anaesthesia. Finally, they reported the need to be able to perform procedures such as tubal ligation, insertion of a suprapubic catheter, caesarian section, forceps delivery or vacuum extraction, and to manage emergencies such as ectopic pregnancy or testicular torsion.

Faced with these findings, the 'knee-jerk' reaction of universitybased clinicians may well be to add more courses and material to undergraduate programmes. Globally, however, undergraduate medical curricula remain hopelessly overloaded, and ongoing debates fail to address the misguided belief that medical graduates need to 'know everything' before commencing clinical practice as interns. This paper provides an ideal opportunity for the HPCSA, clinician educators and doctors supervising interns to critically review the way in which we prepare medical students for clinical practice in SA.

While university-based academic clinicians have long argued about the list of procedures new graduates should be able to perform, e.g. spinal anaesthesia or a caesarian section, it is clear that COSMOs need these skills to address South Africans' priority health needs. Therefore, if health sciences faculties are to teach socially accountable medicine, the discussion should not focus on the need for mastery of key skills, but rather on the opportune time to teach the necessary knowledge and/or skills, i.e. prior to graduation v. during internship.

A nationally agreed-upon list of the skills medical students should master before graduation has been formulated using a Delphi survey strategy. Senior clinicians, responsible for teaching and supervising medical students and interns, were recruited from all the health sciences faculties for the study (Burch, manuscript in preparation), which should quell the vexed debate about the expected proficiency of graduates entering internship. The remaining skills gap between internship and community service will then be clearly demarcated and specific skills training during internship should be easier to address.

Nkabinda et al's second important finding was that $75 \%$ of COSMOs expressed a need for specific training in dermatology, ophthalmology, otorhinolaryngology and orthopaedics. ${ }^{[7]}$ This is in keeping with the opinions expressed by clinicians teaching in these disciplines when we, as members of HPCSA accreditation panels, undertake reviews of the undergraduate medical programmes offered in SA's health sciences faculties.

Nkabinde and colleagues are to be congratulated. Not only have they identified basic priority healthcare needs of the 'communities, region and nation we are mandated to serve, ${ }^{\left[{ }^{[4]}\right.}$ but their work also dovetails with a forthcoming study by the HPCSA's Subcommittee for Internship Training of the Medical and Dental Professions Board (MDB). This study will evaluate the quality and adequacy of internship training from the perspective of COSMOs' supervising clinicians and patients. This additional information should support the drive by the MDB of the HPCSA to ensure that interns are appropriately equipped to address priority health concerns in the communities where they will work as COSMOs. Health Sciences faculties that do not critically reflect on the key messages of this paper may ultimately limit the ability of their medical graduates to respond to the global call to practice socially accountable medicine.

Vanessa Burch ${ }^{1,2}$

Ben van Heerden ${ }^{2,3}$

${ }^{1}$ Department of Medicine, Faculty of Health Sciences, University of Cape Town, South Africa

${ }^{2}$ Undergraduate Education and Training Subcommittee, Medical and Dental Professions Board of the Health Professions Council of South Africa, Pretoria, South Africa

${ }^{3}$ Centre for Health Professions Education, Faculty of Medicine and Health Sciences, Stellenbosch University, Tygerberg, South Africa

\section{Corresponding author: B van Heerden (bbvh@sun.ac.za)}

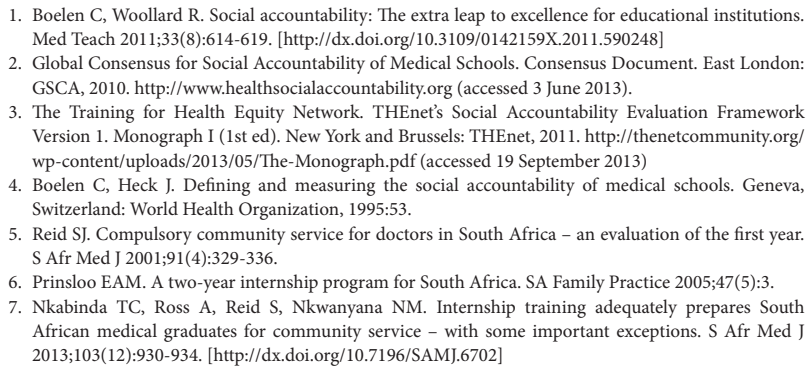
Switzerland: World Health Organization, 1995:53.

Reid SJ. Compulsory community service for doctors in South Africa - an evaluation of the first year S Afr Med J 2001;91(4):329-336.

6. Prinsloo EAM. A two-year internship program for South Africa. SA Family Practice 2005;47(5):3.

7. Nkabinda TC, Ross A, Reid S, Nkwanyana NM. Internship training adequately prepares South African medical graduates for community service - with some important exceptions. S Afr Med J 2013;103(12):930-934. [http://dx.doi.org/10.7196/SAMJ.6702]

S Afr Med J 2013;103(12):905. DOI:10.7196/SAMJ.7198 